\title{
Performance Assessment Framework for Private Finance Initiative Projects in Malaysia
}

\author{
Nor Suzila Lop ${ }^{1, a}$, Kharizam Ismail ${ }^{2}$ and Haryati Mohd Isa ${ }^{3}$ \\ ${ }^{1}$ Centre of Postgraduate Studies, Universiti Teknologi MARA, Seri Iskandar Campus, Seri Iskandar, 32610, Perak, Malaysia. \\ ${ }^{2,3}$ Faculty of Architecture Planning and Surveying, Universiti Teknologi MARA, Seri Iskandar Campus, Seri Iskandar, 32610, Perak, \\ Malaysia.
}

\begin{abstract}
Private Finance Initiative (PFI) is viewed as restructuring the previous privatisation concept in delivering value for money for the Malaysian public infrastructure. Among the restructuring efforts in the privatisation is specifying the standard assessment of private concessionaires' performance through the execution of key performance indicators (KPIs) where the private concessionaires' performance is benchmarked against the government's standard. KPIs have served as useful tools in assessing performance of PFI projects. However, there is still lacking on determination methods performed to define and measure this KPIs and the absence of guidelines or a framework is also an issue in the implementation of the PFI procurement in Malaysia. Therefore, the objectives of this paper is to investigate the notion of performance assessment model approaches globally (i.e. UK, China, Australia, Serbia and Malaysia) and to identify direction for PFI performance assessment tools (KPIs) to be practiced in Malaysia. Based on the consideration of these models, this research paper propose an initial framework of performance assessment for PFI projects in Malaysia. The framework is deliberate to cover the performance of PFI at the operation and maintenance phase. The outcomes of this paper can serve as a theoretical base for the development of comprehensive and effective performance assessment for PFI projects in Malaysia.
\end{abstract}

\section{Introduction}

Private Finance Initiative (PFI) is a type of Public Private Partnership (PPP) with referring to contractual arrangement between public and private sectors, where the private sectors delivers a good service and successful performances within stipulated concession period. Private Finance Initiative (PFI) projects are designed to fund long-term public infrastructure and services provided for the whole life cycle of PFI projects. During this cycle, PFI performances could be affected by a number of factors and their interactions, which might cause the inefficiency and ineffectiveness of the projects. According to [1], in the UK and Australia, service failure and poor performance in maintenance work for noncompliance with output specification is frequently reported within PPP/PFI projects. Additionally, PPP/PFI have always stressed on the Value for Money (VfM) and innovation on the basis of harmonious partnership [2]. According to [3], value for money (VfM) in PFI project crucially dependent on performance monitoring to provide certain incentives for improvement. These monitoring also is to ensure that the facilities provided and service delivery is in accordance with the client's requirement, as was set out in the output specification.

Performance measurement is essential to make PFI projects function effectively and efficiently. In order to measure the projects performances and for executing a

\footnotetext{
${ }^{a}$ Corresponding author: suzila8478@gmail.com
}

benchmarking approach, the one that must be establish is key performance indicators (KPIs). It is crucial in determining the overall success of the PFI projects. An absence of effective performance measurement in PPPs will be reflected from the depreciation of standards below optimum service quality of infrastructures and will contribute to the failures delivery of PPP projects $[4,5,6$, $7,8,9,10,11,12]$. In addition, the clients of the public sector can achieved value for money (VfM) from the usage of properties that meets their requirements, thus satisfying the main objectives of the PPP/PFI procurement mechanism [13].

Within this context, a research was presented to investigate the extent of this problem within PFI projects in Malaysia. Hence, this study investigates two fundamental issues: first, the notion of performance assessment for PFI projects undertaken in the different countries such as UK, China, Australia, Serbia and Malaysia. Second is to identify direction for PFI performance assessment tools (KPIs) to be practice in Malaysia.

\section{Private Finance Initiative}

\subsection{Overview of Private Finance Initiative (PFI)}

PFI was initiated in 1992 under the United Kingdom 
(U.K.) government and has transformed its approach from the traditional delivery of providing a range of public service projects, such as hospitals, schools, prisons, roads, etc., to privately finance, design, construct, manage, and operate these facilities. Public Private Partnership (PPP) is a procurement method that has been successfully implemented by many countries worldwide such as United Kingdom, Australia, USA, China, Hong Kong, France, Germany, Japan as well as Malaysia. The main guiding principles are to use the private sector in the provision of constructed facilities by using a whole life approach (delivering and maintaining it) within the whole life of concession period. The whole life approach includes the operation and maintenance phase of the projects throughout the entire concession period, which is about 25-30 years [14, 15].

\subsection{Private Finance Initiative (PFI) in Malaysia}

Private sector participation in providing facilities and public services is not new in Malaysia where it has been implemented since the $1980 \mathrm{~s}$. The adverse impact of the world economic recession prompted the government to seek assistance from the private sector for the development and economic activities of the country [16]. Currently, most of the public projects have been plagued by delays and shoddy workmanship, which is inherently seen as a major problem to the government $[17,18]$. As a result of this situation, the maintenance repairs cost are increased, causing the Malaysian Government is reluctant to spend huge amount of money on the development of public infrastructure projects as public sector capital fund is insufficient [19]. Therefore, to bridge these issues, the Malaysian Government is turning to alternative way of Private Finance Initiative (PFI) for transforming the public projects.

PFI in Malaysia was originally initiated by the Malaysian Government through the Ninth Malaysia-Plan (2006-2010) under the National Privatisation Plan [20] and officially implemented in year 2009. It was further evolved in the Tenth Malaysia Plan (2011-2015) under the National Privatisation Plan [21]. In Tenth Malaysia Plan, it was clearly articulated the rationale for encouraging PPP/PFI procurement as the "engine of growth" in development of Malaysian Infrastructures. One of the agenda established in the Tenth Malaysian Plan are to encourage the development of Bumiputeras' entrepreneurship to embark on private projects under PPP/PFI procurements [22]. Infrastructure development is one of a key component to unlock potential economic activities and to support sustainable economic growth. Thus, as an effort, Malaysian Government will continue to place emphasis on infrastructure development as part of the economic transformation.

\subsection{Issues of PFI in Malaysia}

PFI have been seen as an arrangement where public and private sectors work together in implementing social and economic projects and it was designed to focus on value for money (VfM) approach, its timely implementations and efficient for facilities management. Fundamentally, the PFI programme was aimed at facilitating greater participation of the private sector to improve the delivery of infrastructure facilities and public services [23]. In addition, [17] highlight that the Malaysian PFI deviates from the basic definitions of international PPP/PFI framework. The Malaysian version of PFI will be financed by the EPF loans in which the amount was published in the Ninth Malaysian Plan. In order to facilitate the implementation of PFIs, the Ministry of Finance Malaysia has acquired a substantial amount of funds to facilitate the first wave of PFI implementation in Malaysia [17]. In Ninth Malaysian Plan, RM20 billion are allocated for these PFI projects. Nevertheless, there is a view that the government could still bear the risk to a certain extent, in particular if any of the PFI project becomes unsuccessful.

In Malaysia's scenario, the concept of PFI are lagging behind compared to other experiences countries such UK and Australia. The absence of key performance indicators (KPIs), is identified as one of the core criticisms towards the implementation of PPP in Malaysia [24, 25]. The public and private sectors' exertion in establishing KPIs, and the methods undertaken to define and measure these KPIs, are also among the crucial issues in performance evaluation. Even though a lot of studies on KPIs have been conducted in aiming to improve the performances, nonetheless, KPIs is continuously debated. Another issues with regards to PFI projects in Malaysia is the absence of any guideline or framework for the implementation of PFI procurement system [26]. Since PFI procurement scheme is still at an infant stage in Malaysia, the establishment of a framework is paramount in order to provide a better understanding of the execution of the complex scheme of financing, as well as the establishment of key performance indicators (KPIs) for assessing overall project performance. Despite the tremendous growth of PPP implementation in Malaysia, the PPP arrangements have been constantly reviewed and revised by the Malaysian government to improve the present practice of PPP implementation to ensure the achievement of its ultimate goal and objectives.

\subsection{Performance Assessment in PFI Projects}

The key principle of PFI is the link between performance and incentive payments to the private sector based on the successful delivery of services to the public sector. However, the service delivery aspects of PFI projects cannot be examined until projects become operational. Yet, during the operational phase, service delivery can be frequently assessed to determine compliance with the output specification and payment deductions for the performance failures in accordance with the payment mechanism [27].

Performance assessment is an important process in relation to the success and performance of PPP/PFI projects and however, it has received limited attention under the life-cycle perspective [5]. [28] define the

\footnotetext{
a Corresponding author: suzila8478@gmail.com
} 
performance assessment as a process or a set of metrics used to quantify and report the effectiveness and efficiency of the action performed towards organisations' objectives. While, [29] in their study describe that, performance assessment are refers to the selection and use of quantitative measures (item that can be quantify based on the measurement units) and qualitative measures (item that can be quantify based on satisfaction level). The assessment is regarding project capacities, processes and outcomes to inform the public or designated public agency about critical aspects of a project. Thus, the performance assessment associated with VfM in a PPP/PFI project is a complicated process, and the uses of absolute time and cost measurements do not reflect the complexity relating to PPP delivery [30]. Consequently, the assessment of PPP/PFI projects is more difficult than traditional projects as there involved a lot of stages (e.g. documentation, financing, taxation, technical details, and sub-agreements) and risks (e.g. market risks and project risks) that arise from the complexity of the long-term contractual arrangement, which can change dynamically over the projects' lifecycle [31]. Theoretically, an ideal performance assessment system in Public Private Partnership (PPP) can contribute to an effective assessment of PFI projects performance and benefited to the multiple stakeholders.

\section{Methodology}

An in-depth and critical literature review is conducted in this study. It reviews theoretically on the PPP/PFI performance assessment models developed globally in the UK, China, Australia, Serbia and Malaysia. Based on various developed model of performance assessment from different countries, the proposed initial framework for Malaysian approached are established. Further study was plan to be conducted by comprehensive empirical research in the form of questionnaires and case studies (semi-structured interview) followed by the development and validation of performance assessment framework.

\section{Synthesis of Performance Assessment Models}

Theoretically, there are several methods that performance assessment can be structured and applied. A literature review of the existing performance assessment models in PPP/PFI projects as shown in Table 1 adopted from the UK, China, Australia, Serbia and Malaysia. These models were chosen in this study due to their experienced and establishment in implementing PPP/PFI and good track records in terms of performances that could be learned, in particular from the performance assessment view of point. There are six variables identified to compare the assessment model internationally. These are types of performance assessment tools, criteria in selecting performance indicators, categories of KPIs, KPIs measures, types of infrastructure projects, implementation stage, and weakness of the model. Undeniably, the UK is a pioneer and originator of PFI approach in terms of contract procurement as well as performance assessment, therefore, internationally comparative study has been made and discussed as follows:

\subsection{The UK Performance Assessment Model}

The UK performance assessment model of PFI project by [32] outlines a process starts by looking into performance assessment tools use in the PPP/PFI projects. This model are designed to use key performance indicators (KPIs) as a tools in assessing PFI projects performance. Development of KPIs by UK model are depending on certain criteria which are complex, defined, measurable, simple and understandable. Complex means the KPIs must be detailed covering all aspect of sustainability and stakeholder satisfaction. While, defined, simple and understandable is the clear, systematic and wellstructured of KPIs developed. KPIs also must be able to measure so as to evaluate the performance of PFI projects. All the criteria need to be integrate when constructing and establishing performance indicators. In making robust assessment of PFI projects performance, the development of KPIs are takes into consideration of the effective measures which include qualitative measures and quantitative measures. Qualitative measures includes indicators on satisfaction level (i.e. multiple stakeholders) whereas, quantitative measures are includes indicators that can be measures based on the measurement unit (i.e. meter, square meter, etc.).

The UK model has divided the KPIs into four categories of dimensions which are social, economic, environmental and technical. These covers most of the critical sustainability issues through the wider PFI project environment. The study conducted by [32] are concentrating on the social, environmental and economic infrastructure and data was collected for construction and operation \& maintenance phases. However, there are some limitation and barriers identified in the development of UK's KPIs model for instance lack of experience from the consultant on the sustainability issues and lack in depth analysis of individual projects. Nevertheless, the absence of detailed measures (weightage system) for each indicators identified as a weakness in the model.

\subsection{The China Performance Assessment Model}

The China performance assessment model by [4, 33] are using key performance indicators (KPIs) as a tools in assessing performance of PFI projects. It is differ from the UK model where KPIs are comprehensively used in assessing sustainability PFI projects performance. Key performance indicators developed in China performance assessment model are basically based on the main criteria which are identical to the UK model which are defined, complex and measurable. KPIs must be specific, clear and focused to avoid misinterpretation or ambiguity. This model has categorized the dimensions into five categories which are physical characteristic, financing and marketing, innovation and learning, stakeholders and projects process.

\footnotetext{
a Corresponding author: suzila8478@gmail.com
} 


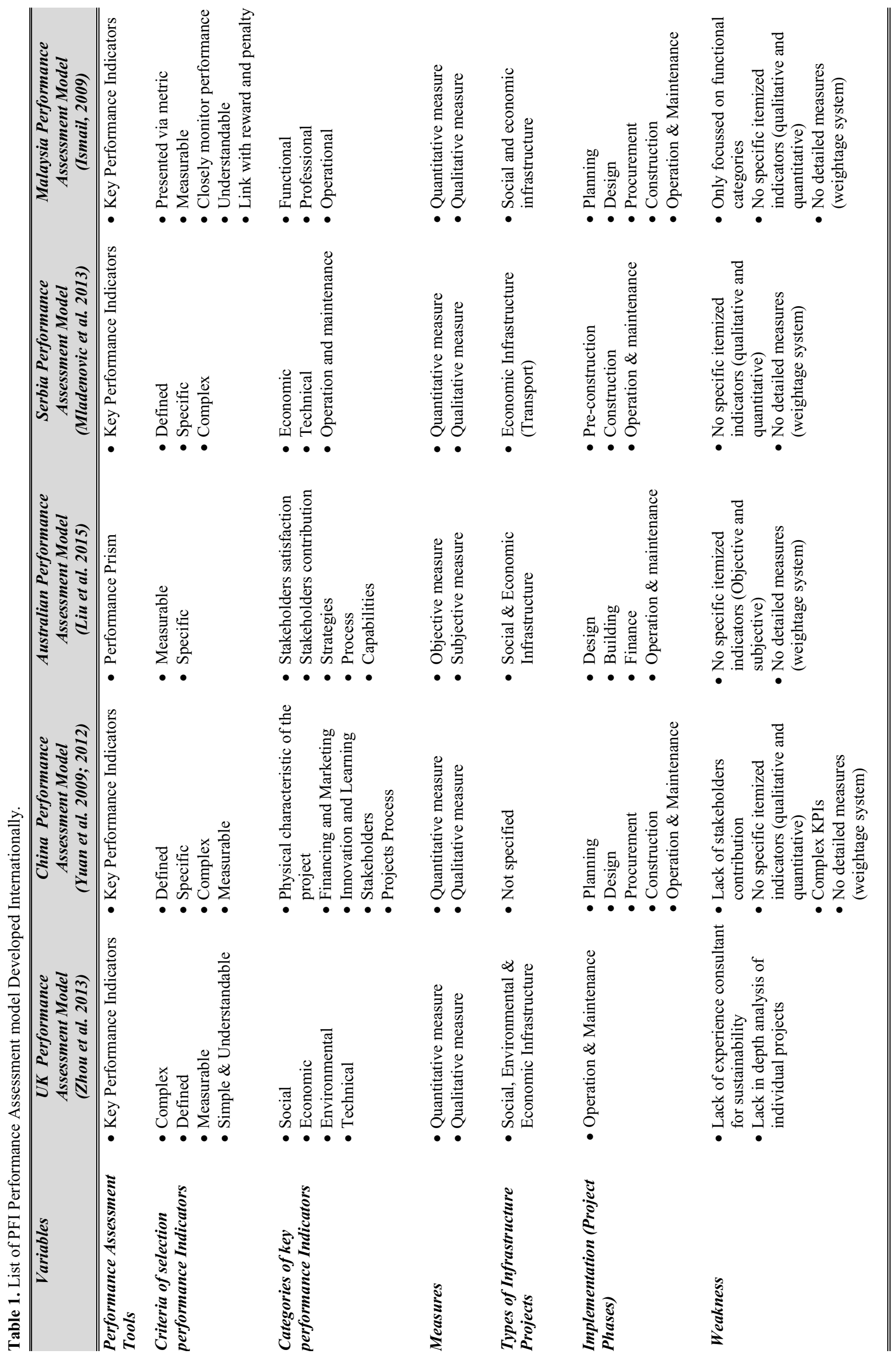


It also similar to the UK model where quantitative and qualitative measures are considered in the development of KPIs. Even though qualitative and quantitative measures of KPIs are considered in this model, but there is no specific itemized indicators stated to differentiate between qualitative indicators and quantitative indicators. Unfortunately there are some weakness determine from the model such as lack of stakeholders contribution instead of stakeholders satisfaction on the PFI projects performance and lack of detailed measures (weightage system) for each developed indicators. This performance assessment model (KPIs) can be regarded as complex. It covers all dimensions throughout the projects phases. This indicators are derives from the review of literatures, therefore, it should be tested by the empirical study to reduces the number of KPIs.

\subsection{The Australian Performance Assessment Model}

In the context of Australia, the performance assessment tools applied in the model is performance prism. These performance prism by [6] having a similar concepts with key performance indicators (KPIs) but differ in term of the involvement of multiple stakeholder integration and it provide assistance in directing and guiding the design of performance measurement for long-term success. The performance prism comprised of five interrelated facets designed for measurement such as stakeholder satisfaction, strategies, processes, capabilities and stakeholder contribution. The views of stakeholders incorporated in the Performance Prism mean give the ability to overcome the hurdle triggered by multiple stakeholders (shareholders, customers, suppliers, alliance partners, and even intermediaries) in PPP/PFI evaluation. The development of performance prism take into consideration both measurable and specific criteria for each dimensions. This model are also have the similarity with other models in term of subject measures which considering on both objective and subjective measures. It also been implemented for social or economic infrastructure across projects phases (design, building, finance and operation \& maintenance). Nevertheless, the development of an appropriate KPIs and the detailed measures stated in this model is just conceptually and no empirical testing and validation are presented and it demonstrate the weakness of the model.

\subsection{The Serbia Performance Assessment Model}

The need for more efficient and effective public-private partnership (PPP) projects makes performance management of increasing importance, especially with respect to stakeholder expectations. In the context of Serbia model, it was developed key performances indicators (KPI) based on the analysis of critical success factors (CSF) for monitoring of PPP transport projects from the perspective of different stakeholders. The development of KPIs are interrelated with the performance objectives and critical success factors (CSF). According to the authors, [12], the constructed KPIs must be defined, specific and complex. This model was abstract from the review and comparative analysis of existing critical success factors (CSFs) and KPIs in PPP transport projects and it was performed based on stakeholders' objectives and different project attributes. Therefore, the KPIs was grouped into three essential groups depending on the aspect of the project which are economic, technical, and operation and maintenance.

In making dynamic assessment of PFI projects performance, the constructed KPIs in this model introduced a two layers approach for the assessment of PPP projects. The first stage was based on evaluation of project ultimate objectives from the standpoint of each stakeholder, i.e. profitability for private sector, effectiveness and value for money for public sector, and level of service for users. An adjusted and weighted combination of fulfilment of the specific stakeholder objectives leads to an overall approach (second layer) of describing a PPPs success or failure. Therefore the assessment for PFI performance considers both the qualitative and quantitative measures, which are identical to the UK, China and Australia practices. It also covers all stages during life cycle projects (pre-construction, construction, and operation \& maintenance phase). To assess the performance of PFI projects consequently, it requires detailed measures such as weightage system in order to attain value for money (VfM). Nonetheless, the absence of the appropriate detailed measures perceived as a weakness of the model.

\subsection{The Malaysian Performance Assessment Model}

PFI in Malaysian viewed of point is generally labelled as privatisation instead of PFI even though PFI is differed from privatisation to a certain extent. Insufficiency of information by the public and private sectors, which have implemented PFI, has been the reason why PFI projects in Malaysia has never been evaluated comprehensively. Given that, for the Malaysian context, a key performance indicators (KPIs) approached is used to measure performance of the PFI projects. It is studied by [34], which divided the KPIs into three categories: functional, professional and operational. The formation of KPIs is fundamentally based on the criteria such presented via metric, measurable, closely monitor performance, understandable and KPIs must link with reward and penalty. All listed criteria are vital to be integrated when choosing and constructed the KPIs. Essentially, this model are developed by considering both qualitative and quantitative measures similarly with other countries. Malaysian has adopted PFI for the social and economic infrastructure where most of the financed (RM20 Billion) are allocated for the social infrastructure (health, education and etc.).

Thus, the KPIs been categorized into three (functional, professional and operational), essentially, it is completely covers all stages of the life cycle projects such planning, design, procurement, construction and operation \& maintenance.

\footnotetext{
a Corresponding author: suzila8478@gmail.com
} 


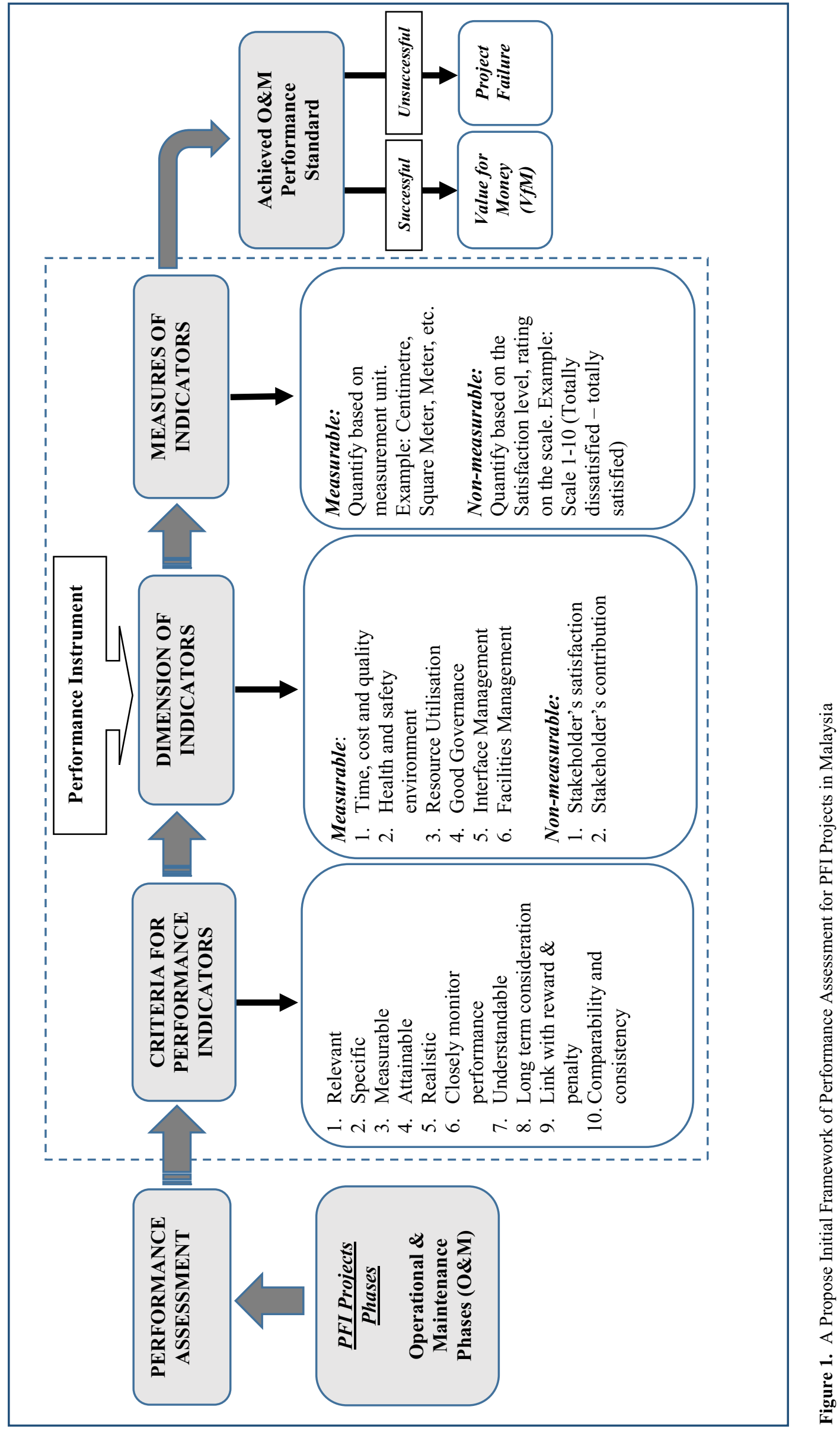


Even though the development of an appropriate KPIs identified in this model has been empirically tested and validated, but there are only verified for the functional category and future recommendation is suggested to continue for the other categories (professional and operation). The other weakness of this model is similarly to the other countries (UK, China, Australia and Serbia) which detailed measures and itemized indicators (qualitative and quantitative) is not specifically spelt out.

\section{A Proposed Initial Framework of Performance Assessment for PFI projects in Malaysia.}

Based on preliminary literature review and understanding of performance assessment models adopted from various countries (UK, China, Australia Serbia as well as Malaysia). The proposed framework for PFI performance assessment in Malaysia is initially developed as illustrated in Figure 1. In this framework, performance assessment is designed to embrace the specific phases of the PFI projects which is focused on the critical phases throughout project life cycle (operation and maintenance phases). It is due to the facts that every project phases have their own objectives and goals that need to be achieved. The implementation of performance assessment via KPIs approach is needed to achieve performance standards, quality service provided and the most significant goals is getting value for money (VfM). Therefore, key performance indicators are one of the effective performance instruments used to assess the performance and success of the PFI projects specifically in Malaysia. The prime factors in developing an effective key performance indicators are by embedding the important criteria (relevant, specific, measurable, attainable, realistic, and etc.) with every possible indicators (measurable and non-measurable). The terms measurable and non-measurable have similar meaning with the qualitative and quantitative measures. For this version of initial framework, terms measurable and nonmeasurable is used. In addition, the integration between criteria, indicators and weightage system is important part in this study to determine 'what to measure' and 'how to measure' the performance of the PFI projects. Weightage system for the measurable items are the items that can be quantify based on the measurement units (i.e meter, numbers, cost, time etc.), where non-measurable items are items that can be quantify based on satisfaction level (i.e customer satisfaction, client satisfaction, etc). Thus, establishing an important criteria is essential as a guidance for selecting the most appropriate indicators. As a result, lack of stakeholder's satisfaction and the linkages between indicators and measures for the assessment strategy shows the gaps for the future study.

\section{Conclusion}

This paper anticipate to review, synthesize and develop a framework of performance assessment for PFI projects in Malaysia based on the various models of performance assessment from the UK, China, Australia, Serbia as well as Malaysia. It also intend to identify the direction and usefulness of performance assessment tools (KPIs) to be practiced for PFI projects in Malaysia. Most of the models are applying KPIs as a tools to assess the performance of PFI across projects phases. However, there is no single model that has been developed to integrate KPIs weighting system for measuring each indicators. As a result, the study was found gaps through the listed weakness, therefore, it is vital for the Malaysian Government to develop a framework for assessing PFI projects performance especially for the critical phases of operation and maintenance that involved lengthy concession period (25-30 years).

The research presented in this paper is initially and part of an ongoing $\mathrm{PhD}$ research at the faculty of Architecture, Planning and Surveying, UiTM to develop a framework of an integrated performance assessment for PFI projects in Malaysia. The result of the study would provide an insight into the Malaysian construction project development and forms the basis of a valuable guideline, especially to public and private sectors in Malaysia.

\section{References}

1. NAO. The Performance and Management of Hospital PFI Contracts, 68. (2010).

2. Yuan, J., Skibniewski, M. J., \& Li, Q. Managing the Performance of Public Private Partnership Projects to Achieve Value for Money: Key Performance Indicators Selection. In International Conference On Multi-National Construction Projects, pp. 1-16 (2008).

3. Robinson, H. S. H., \& Scott, J. Service Delivery and Performance Monitoring in PFI/PPP Projects. Construction Management and Economics, 27(2), pp. 181-197 (2009).

4. Yuan, J., Zeng, A. Y., Skibniewski, M. J., \& Li, Q. Selection of Performance Objectives and Key Performance Indicators in Public-Private Partnership Projects to Achieve Value for Money. Construction Management and Economics, 27, pp. 253-270. (2009).

5. Liu, J., Love, P. E. D., Davis, P. R., Smith, J., \& Regan, M. Performance Measurement Framework in PPP Projects. (2013).

6. Liu, J., Love, P. E. D. D., Smith, J., Regan, M., \& Palaneeswaran, E. Review of Performance Measurement: Implications for Public-Private Partnerships. Built Environment Project and Asset Management, 5(1), pp. 35-51. (2015).

7. Regan, M., Smith, J., \& Love, P. E. D. Impact of The Capital Market Collapse on Public Private Partnership Infrastructure Projects. Journal of Construction Engineering and Management, 137(1), pp. 6-16. (2011).

8. Hodge, G. The Risky Business Of Public - Private Partnerships. Symposium, 63 (December), pp. 3749. (2004).

\footnotetext{
${ }^{\mathrm{a}}$ Corresponding author: suzila8478@gmail.com
} 
9. Yong, H K. Public-Private Partnerships Policy and Practice, London: C. Secretariat. (2010).

10. VAGO. Report of the Auditor-General on the Finances of the State of Victoria, 2001-2002, (2002).

11. House of Commons. The Operational Performance of PFI Prisons: Forty-ninth Report of Session 20022003. (2003).

12. Mladenovic, G., Vajdic, N., \& Wu, B. Use of Key Performance Indicators for PPP Transport Projects to Meet Stakeholders' Performance Objectives. (2013).

13. Oyedele, L. O. Avoiding Performance Failure Payment Deductions in PFI/PPP Projects: A Model of Critical Success Factors. Journal of Performance of Constructed Facilities, (JUNE), 259. (2013).

14. El-Haram, M. a., \& Agapiou, A. The Role of the Facility Manager in New Procurement Routes. Journal of Quality in Maintenance Engineering, 8(2), pp. 124-134. (2002).

15. NAO. The Operational Performance of PFI Prisons, (June), 55. (2003).

16. Ismail, S., \& Rashid, K. A. Private Finance Initiative (PFI) In Malaysia: The Need for and Issues Related to the Public Sector Comparator (PSC). (2007).

17. Jayaseelan, R., \& Tan, M. PFI-cure for All Ills. The Egde Malaysia, pp. 72-74. (2006).

18. Endut, I.R. Framework For Minimizing Time Overruns of Malaysia Construction Projects. A PhD Thesis, Glasgow Caledonian University. (2008).

19. Netto, A. Malaysia's New Fangled Privatization Fudge. EPU. (2006).

20. Economic Planning Unit (EPU). Streamlining Privatization. Ninth Malaysia Plan 2006-2010, pp. 223-233. (2006).

21. Economic Planning Unit (EPU). The Tenth Malaysian Plan, 2011-2015, Prime Ministeres Department, Putrajaya. (2010).

22. PEMANDU. Annual Report: Economic Transformation Programme (ETP), Kuala Lumpur: PEMANDU. (2011).

23. Prime Minister Department. Public Private Partnership (PPP) Guideline, pp. 1-12. (2009).

24. Khaderi, S. S., \& Aziz, a. R. a. Adoption of Private Finance Initiative (PFI) in Malaysian Public Works Projects: Are We Ready? CIB TG72 World Building Congress, pp. 105-120. (2010).

25. Ismail, K. A Value for Money Assessment Framework for Public Private Partnership Approach, PhD, Thesis. (2012).

26. Edge, T. Untested Model for Malaysian Companies. The Edge Malaysia, p. 75. (2006).
27. Akbiyıkl1, R. Performance Assessment of A Private Finance Initiative Road Project. Transport, 28 (February 2015), pp. 11-24. (2013).

28. Neely, A., Gregory, M. and Platts, K., Performance Measurement System Design: A Literature Review And Research Agenda, International Journal of Operations and Production Management, Vol. 25 No. 12, pp. 1228-1263. (2005).

29. Ong'olo, D.O., Public Private Partnerships (PPP): Practice and Regulatory Policy in Kenya. Paper prepared for the Institute of Economic Affairs (IEA) on July 7th 2006, Kenya. (2006).

30. European Commission. Guidelines for Successful Public-Private Partnerships, European Commission, Brussels. (2003).

31. Grimsey, D., \& Lewis, M. Evaluating The Risks Of Public Private Partnerships For Infrastructure Projects. International Journal of Project Management. (2002).

32. Zhou, L., Keivani, R., \& Kurul, E. Sustainability Performance Measurement Framework for PFI Projects in the UK. (2013).

33. Yuan, J., Wang, C., Skibniewski, M. J., \& Li, Q. Developing Key Performance Indicators for PublicPrivate Partnership Projects: Questionnaire Survey and Analysis. Journal of Management in Engineering, 28(3), pp. 252-264. (2012).

34. Ismail, S. Key Performance Indicator for Private Finance Initiative in Malaysia. PhD Thesis. (2009).

\footnotetext{
$\overline{{ }^{a} \text { Corresponding author: suzila8478} @ g m a i l . c o m ~}$
} 